\title{
USE OF SPATIAL FEATURES BY FORAGING INSECTIVOROUS BATS IN A LARGE URBAN LANDSCAPE
}

\author{
Rafael Avila-Flores* and M. Brock Fenton \\ Department of Biology, York University, Toronto, Ontario M3J 1P3, Canada \\ Present address of RA-F: Department of Biological Sciences, University of Alberta, Edmonton, Alberta T6G 2E9, Canada \\ Present address of MBF: Department of Biology, The University of Western Ontario, London, Ontario N6A 5B7, Canada
}

\begin{abstract}
We analyzed the patterns of habitat use by insectivorous bats in Mexico City, one of the largest and most populated cities of the world. We tested the hypotheses that richer patches of food, expected in more vegetated areas, have higher bat activity levels, and that fast-flying species benefit most from urbanization. We compared activity of insectivorous species and relative abundance of insects in 5 habitats (large parks, small parks, illuminated open areas, residential areas, and natural forest). Sampling of bat activity and insects was conducted every 2 weeks in 12 sites per habitat during summer 2002. Measures of bat activity were based on 3,600 oneminute sequences of sound that were recorded and analyzed. The average number of taxa per site was significantly higher in the natural forest than in urban habitats, but overall bat activity was significantly higher in large parks and illuminated open areas than in small parks, residential areas and natural forest. Vespertilionid bats (Eptesicus fuscus, Myotis, and an unidentified species), along with Eumops perotis, occurred almost exclusively in extensive green areas (large parks or natural forest). The molossid Nyctinomops macrotis made the broadest use of the urban-natural mosaic, whereas Tadarida brasiliensis used urban sites (illuminated areas and large parks) more intensively. Insect abundance was higher in large parks and natural forest, and it was significantly correlated with overall bat activity and with the number of taxa recorded per site. The observed patterns of habitat use and foraging can be explained by considering the flight and echolocation performance of species. Although some species successfully exploited highly urbanized sites, large areas with vegetation are needed to maintain the most diverse insectivorous bat fauna in Mexico City.
\end{abstract}

Key words: bat activity, echolocation, habitat use, insectivorous bats, megacities, Mexico City, urbanization

Reduction, fragmentation, and transformation of natural habitats pose some of the greatest threats to global biodiversity (Primack 2000). Extreme examples of all of these processes occur in urban settings. Here, natural or seminatural habitats have been reduced to small and highly disturbed patches of vegetation distributed within a human-made matrix. The effects of urbanization on overall biodiversity depend on the nature of urbanization and on the characteristics of the regional landscape (Clergeau et al. 1998; Hardy and Dennis 1999; Savard et al. 2000). However, as a general rule, the legacy of urbanization is a decrease in species richness and diversity in affected areas (e.g., Germaine and Wakeling 2001; Kozlov 1996; Savard et al. 2000). Additionally, biodiversity in urbanized areas with high human density is often characterized by invasive and nonnative (introduced) species (Gilbert 1989).

\footnotetext{
*Correspondent: rafael.avila-flores@ualberta.ca
}

\section{(C) 2005 American Society of Mammalogists www.mammalogy.org}

Flying species of vertebrates are thought to be less affected by urbanization because they can move more readily between patches than can nonvolant species (Gilbert 1989). However, richness and diversity of avian communities tend to decrease with increased urbanization and to increase with proportion of urban green areas (e.g., Clergeau et al. 1998; Fernández-Juricic 2000; Fernández-Juricic and Jokimäki 2001; Gavareski 1976; Jokimäki 1999; Savard et al. 2000; Sodhi et al. 1999). In the case of bats, most available information about the use of urban habitats comes from occasional records of individuals captured or found in cities. Studies investigating how bats exploit urban areas have focused on bat communities in North America and Europe (e.g., Everette et al. 2001; Gaisler et al. 1998; Geggie and Fenton 1985; Gehrt and Chelsvig 2003; Kurta and Teramino 1992). In general, results from previous studies are scale-dependent. On a large scale, cities may support higher or lower levels of bat activity than areas with different land use, depending on the nature of the surrounding landscape (Furlonger et al. 1987; Gehrt and Chelsvig 2003; Russo and Jones 2003; Vaughan et al. 1997; Walsh and Harris 1996). On 
a smaller scale, wooded areas, water bodies, and streetlamps are important for the species that have been studied (Everette et al. 2001; Furlonger et al. 1987; Gaisler et al. 1998; Gehrt and Chelsvig 2003; Kurta and Teramino 1992; Sánchez et al. 1989).

It is not clear why some species of bats use urban settings and others do not. The occurrence of bats in a given location depends on the presence of suitable food and roosts in appropriate areas, so foraging and roosting requirements of species should provide insight into bat-city relationships. Urban environments may offer abundant potential roosts for bats that roost in crevices and hollows (Everette et al. 2001; Geggie and Fenton 1985; Jones and Jayne 1988; Sánchez et al. 1989), but there is no quantitative support for this assumption. Availability of roosts as limiting factors does not explain why some building-dwelling insectivorous species (e.g., Myotis yumanensis) rarely occur in highly urbanized areas (Evelyn et al. 2004). Available information on insectivorous bats suggests that the most common species in cities are those often foraging on high densities of insects found near white-light lamps (Furlonger et al. 1987; Gaisler et al. 1998).

Observations of bats foraging around streetlamps suggest that relatively fast-flying species emitting narrow-band echolocation calls most often exploit these clusters of insects (Blake et al. 1994; Hickey et al. 1996; Rydell 1992; Rydell and Racey 1995; Schnitzler et al. 1987). This association between relatively fast-flying bats and streetlamps generated the suggestion that these species are better suited to exploit these kinds of insect accumulations in open areas than are slow-flying species (Rydell 1992; Rydell and Racey 1995). However, this hypothesis is challenged by the fact that slower-flying species sometimes forage around lamps (Bell 1980; Fenton and Morris 1976; Furlonger et al. 1987). An alternative hypothesis is that slower-flying bats are at higher risk of predation than fast-flying bats when foraging in lighted areas (Rydell and Racey 1995).

The purpose of this study was to compare levels of insectivorous bat activity in different urban settings in Mexico City, a subtropical megacity. We monitored relative insect abundance to explore relationships between bat activity and food availability and compared bat activity in urban and nearby natural forest with no urbanization to gain insight into the influence of urbanization on the native bat assemblage. We hypothesized that more natural and vegetated habitats would support higher levels of insect abundance and thus higher levels of bat activity and higher species richness than more urbanized sites. Our subtropical urban bat assemblage included molossids, fast-flying species not represented in previous studies of bats in cities. We used our data to indirectly test predictions of the "fast-flight advantage hypothesis" for bats foraging under lighted conditions.

\section{Materials ANd Methods}

Study area and sampling sites.-The Mexico City metropolitan area is located in central Mexico, at the southernmost limit of the Nearctic region (Arita and Ortega 1998). The Mexico City metropolitan area extends over more than $1,100 \mathrm{~km}^{2}$ (Ezcurra and Mazari-Hiriart 1996) and encompasses the large urban area north of Distrito Federal
(Mexico City proper) and some adjacent small cities corresponding politically to Estado de Mexico. The lowest and dominant altitude for most of the Mexico City metropolitan area is $2,240 \mathrm{~m}$, but it increases slightly from city center to southern and western areas. The predominant climate in the urban area is sub-humid temperate (annual mean temperature around $15^{\circ} \mathrm{C}$ ) with rain occurring during the summer (slightly more humid in western, southern, and southwestern areas). This climate becomes semidry, but still temperate (annual mean temperature $12-16^{\circ} \mathrm{C}$ ) and rainy during the summer, toward northeastern Mexico City (INEGI 2001). Grasslands and desert scrub are the dominant vegetation in northern and eastern areas, whereas southeastern lowlands are dominated by agricultural fields; gradients of oak-pine-fir forests are present in relatively large areas south, east, and west of the city (Ezcurra 1998; INEGI 2001).

We conducted fieldwork entirely in Mexico City proper, within the Distrito Federal. We employed a stratified study design to ensure representation of contrasting urban features within different geographic and climatic zones of the Mexico City metropolitan area. First, we chose 3 main 10-km-diameter areas located in northeastern (NE), west-central (WC), and southeastern (SE) Mexico City. Within each of these zones, we selected 4 sampling sites for each of the following urban habitats: large parks ( $>100 \mathrm{ha})$, where the 4 sites were located within the same park ( 2 sites selected in areas covered with vegetation and 2 at the shore of artificial lakes); small parks ( $<5$ ha); open areas, illuminated with white-light lamps (plazas, monuments, temples, parking lots, and so on); and highly populated ( $>10,000$ persons $/ \mathrm{km}^{2}$ according to INEGI [2001]), concrete-dominated sites. The large parks were Bosque de San Juan de Aragón (NE; 140 ha), Bosque de Chapultepec (WC; 428 ha), and Parque Ecológico de Xochimilco (SE; 215 ha). Sampling sites, separated by at least $200 \mathrm{~m}$, were arbitrarily established based on security, traffic, and access factors, but never considering a priori bat presence or absence. In total we sampled 12 presumably independent sites (replicates) per habitat. Complete replication of large parks was not possible because of the low number of suitable parks in the city.

For comparison, we selected 12 sites in a natural forest located in the Milpa Alta mountain area, Distrito Federal, $11 \mathrm{~km}$ southeast of suburban Mexico City. Sites were established every $300 \mathrm{~m}$ along an uphill, dirt road surrounded by natural vegetation. The Milpa Alta area is part of the Sierra del Chichinautzin Mountain Range, and comprises the lowest (in altitude) well-preserved natural forest in the Mexico City region. Sampling points ranged in altitude between 2,800 and $2,950 \mathrm{~m}$, and the vegetation along the transect was dominated by pineoak, pine, and fir forests supporting a dense shrub stratum (Navarro 2002). Climate in this area has been described as semicold with abundant rain during the summer (annual mean temperature of $12^{\circ} \mathrm{C}-$ INEGI 2001).

Acoustic sampling of bat activity.-We visited each sampling site every 2 weeks between late May and late August 2002 to monitor bat activity, for a total of 6 sampling periods. At each site, we recorded echolocation calls for $5 \mathrm{~min}$ in 2 periods, early (within $2.5-3.0 \mathrm{~h}$ after dusk, starting at around $2030 \mathrm{~h}$ ) and late (within 2.5-3.0 h starting at around $2300 \mathrm{~h}$ ). However, only one 10-min period rather than two 5 -min periods was usually recorded in 5 of the illuminated open locations because the lights were typically turned off at $2300 \mathrm{~h}$. During every sampling night we visited 8 different sites located within the same zone of the city following a specific and fixed route established according to traffic and access. We reversed the order in the next sampling period. In that way, each of the 60 sampling sites was monitored at a variety of times through the entire field season (a 1-way analysis of variance [ANOVA] did not detect differences between sampling times across the 60 sites; $F=0.392$, d.f. $=59, P=1.00$ ). 


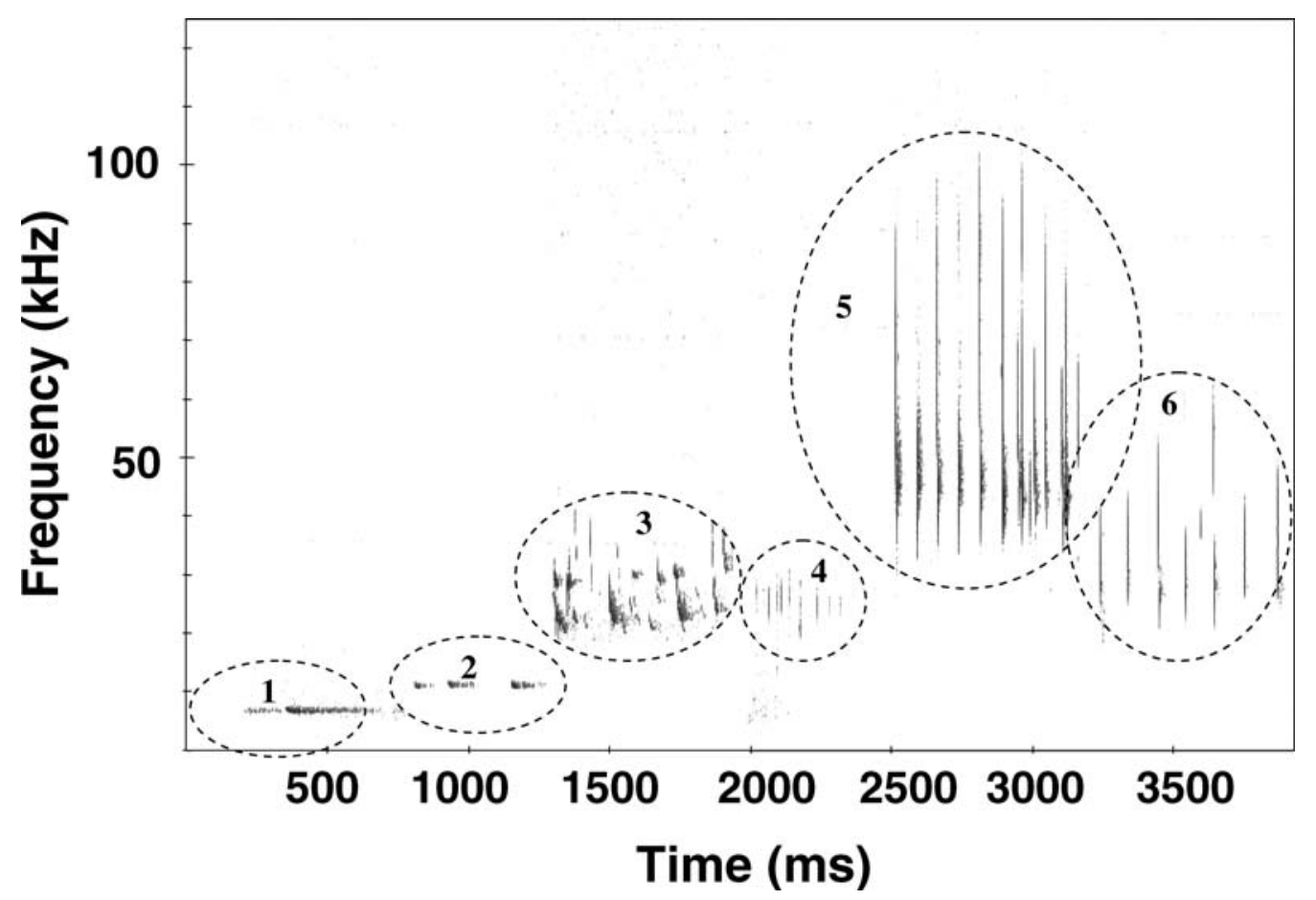

Fig. 1.-Sound spectrograms showing typical calls of the 6 bat taxa recorded in the Mexico City region. Real features of calls are to scale, except for species 1 and 2, where the interpulse interval was shortened. 1 = Eumops perotis; 2 = Nyctinomops macrotis; $3=$ Tadarida brasiliensis; $4=$ unidentified vespertilionid; $5=$ species of genus Myotis; $6=$ Eptesicus fuscus .

High-frequency, real-time recordings were made by using a D-980 bat detector (Pettersson Elektronik AB, Uppsala, Sweden) connected to a portable computer (Dell Latitude, Dell Computer Corporation, Austin, Texas) running BatSound Pro (Pettersson Elektronik AB). Connection to the computer was made through a high-speed sound card (DAQCard-6062E, National Instruments, Austin, Texas), and incoming sounds were highpass-filtered by using an F 2000 Control filter (Pettersson Elektronik AB) set at a low gain. The high-frequency output of the bat detector made it possible to record on computer bat calls emitted at frequencies between 1 and $125 \mathrm{kHz}$ continuously for 1min intervals (hereafter, 1-min recordings may be referred as "files"). Recording settings were defined both in the software (frequency sampling $=250 \mathrm{kHz}$; gain $=2 ; 16$ bits/sample; 44,100 samples/s) and directly in the bat detector (gain $=10 \%$ ), and they were kept constant during the whole field season regardless of site. We used a tripod to maintain the bat detector position at $45^{\circ}$ to the horizontal, $1.2 \mathrm{~m}$ above ground. Geographical orientation of the microphone varied according to the situation to record at the "core" of the habitat: it was directed toward lamps in illuminated open areas, toward water on lakeshores, toward buildings in residential areas, and toward trees in parks. We took measurements of air temperature and recorded time at the beginning of each 5-min recording to control for the possible influence of these factors.

Sound analysis.-To estimate bat activity, we identified and counted the absolute numbers of search-phase bat echolocation calls by visually examining spectrograms (time-frequency-amplitude displays) of every 1-min sequence at 2,000-ms windows by using BatSound Pro software. Because display settings affect the visual perception of calls, we always used the same parameter levels for the spectrogram window (threshold $=9$; amplitude contrast $=3$ ). We only counted calls intense enough to be visually identifiable on spectrograms. In many cases we took quick call measurements on screen to identify species or played the sounds to corroborate the presence of calls. We also counted the number of feeding buzzes (defined as the increase in pulse repetition rate associated with attempted captures of prey-Griffin et al. 1960) to obtain a rough indication of capture rates. As an alternative method to estimate bat activity, we counted the number of files (1-min sequences) at which a minimum of 2 consecutive calls was recorded for given species (equivalent to the acoustic activity index of Miller [2001]).

Extreme call variation and low signal-to-noise ratio (reflecting the low gain used to make recordings in a noisy area) prevented the use of quantitative methods to identify bat calls. Thus, calls were qualitatively identified to species or genus by visually examining spectrograms on BatSound Pro and by matching them with calls recorded from hand-released bats from the Mexico City area. Except for Tadarida brasiliensis, which presents an enormous call variation in the area (Ratcliffe et al. 2004), it was usually easy to separate the taxa just by looking at frequency features (highest frequency, lowest frequency, and frequency with most energy) on spectrograms, but in some instances we also relied on time-dependent parameters (duration and interpulse interval; Fig. 1). To avoid confusing T. brasiliensis with other local species (Sánchez et al. 1989) using constant frequencyfrequency-modulated calls within the same range of frequencies (e.g., Lasiurus cinereus and Eptesicus fuscus-Barclay et al. 1999; Betts 1998; Obrist 1995; O'Farrell et al. 2000), we did not try to identify calls with "intermediate" characteristics. Potential Myotis species recorded during this study include $M$. velifer, $M$. lucifugus, $M$. volans, and M. californicus (Navarro 2002; Sánchez et al. 1989). In Table 1 we show call parameters we used, both from foraging and handreleased animals. Capture, handling, release, and recording of live bats followed guidelines established by the American Society of Mammalogists (Animal Care and Use Committee 1998).

To assign some level of confidence to visual separation of calls and identification of species, we conducted a discriminant function analysis (DFA) by using several good-quality calls recorded during the 
TABle 1.-Averages and coefficients of variation $(\mathrm{CV} \mathrm{s})$ of call parameters for the 6 bat taxa considered in this study. Parameters are shown separately for field-recorded and for reference calls (sample sizes $[n]$ are reported in the same order). Reference calls for Myotis species include calls of $M$. velifer and $M$. volans. $\mathrm{MEF}=$ frequency with most energy $(\mathrm{kHz}) ; \mathrm{LF}=$ lowest frequency $(\mathrm{kHz}) ; \mathrm{HF}=\mathrm{highest}$ frequency $(\mathrm{kHz}) ; \mathrm{DUR}$ $=$ duration $(\mathrm{ms})$; IPI $=$ interpulse interval $(\mathrm{ms})$.

\begin{tabular}{|c|c|c|c|c|c|c|c|c|c|c|c|c|c|c|c|c|c|c|c|c|c|}
\hline \multirow[b]{3}{*}{ Taxon } & \multirow[b]{3}{*}{$n$} & \multicolumn{4}{|c|}{ MEF } & \multicolumn{4}{|c|}{$\mathrm{LF}$} & \multicolumn{4}{|c|}{$\mathrm{HF}$} & \multicolumn{4}{|c|}{ DUR } & \multicolumn{4}{|c|}{ IPI } \\
\hline & & \multicolumn{2}{|c|}{ Sampling } & \multicolumn{2}{|c|}{ Reference } & \multicolumn{2}{|c|}{ Sampling } & \multicolumn{2}{|c|}{ Reference } & \multicolumn{2}{|c|}{ Sampling } & \multicolumn{2}{|c|}{ Reference } & \multicolumn{2}{|c|}{ Sampling } & \multicolumn{2}{|c|}{ Reference } & \multicolumn{2}{|c|}{ Sampling } & \multicolumn{2}{|c|}{ Reference } \\
\hline & & $\bar{X}$ & $C V$ & $\bar{X}$ & $C V$ & $\bar{X}$ & $C V$ & $\bar{X}$ & $C V$ & $\bar{X}$ & $C V$ & $\bar{X}$ & $C V$ & $\bar{X}$ & $C V$ & $\bar{X}$ & $C V$ & $\bar{X}$ & $C V$ & $\bar{X}$ & $C V$ \\
\hline Eumops perotis & 50 & 7.4 & 5.0 & - & - & 6.8 & 4.0 & - & - & 8.2 & 5.9 & - & - & 57.9 & 39.4 & - & - & 1,369 & 21.5 & - & - \\
\hline Nyctinomops macrotis & 60,40 & 12.0 & 12.8 & 13.1 & 3.3 & 11.3 & 11.3 & 11.8 & 4.3 & 13.0 & 16.2 & 15.6 & 6.8 & 18.6 & 23.5 & 34.6 & 25.9 & 1,203 & 75.9 & 795.4 & 28.1 \\
\hline Tadarida brasiliensis & 130,21 & 27.5 & 13.8 & 30.5 & 16.5 & 26.3 & 13.6 & 28.5 & 11.0 & 30.3 & 17.5 & 33.3 & 19.5 & 13.7 & 16.2 & 9.5 & 16.6 & 239.7 & 38.3 & 231.1 & 27.8 \\
\hline Unknown vespertilionid & 6 & 33.1 & 7.3 & - & - & 27.3 & 5.9 & - & - & 40.5 & 9.0 & - & - & 2.9 & 27.6 & - & - & 62.5 & 17.1 & - & - \\
\hline Eptesicus fuscus & 25 & 34.9 & 7.6 & - & - & 31.0 & 7.9 & - & - & 48.3 & 19.0 & - & - & 6.1 & 16.5 & - & - & 131.4 & 28.7 & - & - \\
\hline Myotis species & 130,31 & 46.8 & 6.7 & 46.6 & 7.0 & 41.1 & 6.2 & 41.9 & 4.3 & 61.4 & 22.0 & 54.1 & 7.2 & 4.4 & 27.0 & 3.4 & 58.8 & 73.6 & 39.0 & 66.4 & 43.9 \\
\hline
\end{tabular}

sampling period (data from Table 1). To construct the model we used the same call parameters employed to visually separate the calls (highest frequency, lowest frequency, frequency with most energy, duration, and interpulse interval). Previously, a multivariate analysis of variance showed that at least some call parameters were significantly different among species (Wilks' lambda $=0.009, F=149.9$, d.f. $=25$, $P<0.001)$. The post hoc DFA indicated 5 functions effective for classifying $99.8 \%$ of calls (all except 1 call of Nyctinomops macrotis), where functions 1 and 2 accounted for $98.5 \%$ of total variance according to corresponding eigenvalues (30.0 and 1.39, respectively). Standardized canonical discriminant function coefficients and correlation coefficients showed that lowest frequency and frequency with the most energy largely determined function 1, whereas duration was strongly correlated with function 2 . These results provided a high level of confidence for visual identification of calls based mostly on frequency parameters and call duration. A more detailed description of call identification is provided by Avila-Flores (2003).

Insect sampling.-We estimated relative insect abundance by using a photographic "trapping" method, a combination of the technique used by Bell (1980) to attract insects and those used by Rydell (1992) and Blake et al. (1994) to photograph and count insects. Photographic trapping provided a general indication of insect availability at each site, bearing in mind the limitations of light-based trapping to estimate food availability for bats (Kunz 1988). At the start of every 5-min bat recording session, we placed on the ground, close to the bat detector, a 43.5-cm-long black-light lamp over a $1-\mathrm{m}^{2}$ white cloth to attract insects. We then took flash photographs with a digital camera (PowerShot G2, Canon Inc., Tokyo, Japan) placed on the cloth 15 $\mathrm{cm}$ above the ground and aimed toward the dark sky. Photographs were taken by using a constant aperture of 8 and a shutter speed of $1 / 250$, fixing the focus at $80 \mathrm{~cm}$. The area sampled by this technique was $0.46 \mathrm{~m}^{2}$ per picture (at best focus). Preliminary observations showed that sometimes insects were attracted within the 1st minute after turning the lamp on (as observed by Bell [1980]), whereas other times they accumulated only after some minutes had passed. Therefore, we took 2 photographs at each site during each 5 -min period, 1 at the 1 st minute after turning on the light and a 2nd at the 5th minute. Flying insects appeared in the pictures as bright small dots contrasting with the dark background. We counted the number of insects in each picture by considering only those bright focused dots clearly identifiable as insects (shape and wings evident), often by making use of the zoom tool. To determine the final number of insects sampled at each 5-min period, we only considered the picture with the highest count of insects.

Statistical analyses.-We conducted exploratory analyses to assess the overall influence of temperature and time of recording on bat activity, by using the 5-min intervals as the unit of analysis. Because temperature was significantly associated with habitat (homogeneity of slopes test: $F=8.99$, d.f. $=4, P<0.001$ ), we eliminated this factor from further analyses. We conducted an analysis of covariance (ANCOVA) to control for time of recording, which had some effect on bat activity independent of habitat (slopes were homogeneous). In the ANCOVA, log-transformed number of calls was the response variable, habitat was the factor, and time of recording was the covariate. We used contrast tests to identify pairs of habitats presenting differences in bat activity.

For further statistical analyses, we considered each of the 60 sampling sites as an independent sampling unit, where data for all visits per site were summed and pooled together (temporal variation among visits is discussed by Avila-Flores [2003]). Thus, main comparisons were made between 5 habitats with 12 replicates each. Differences in logtransformed number of calls, log-transformed number of feeding buzzes, number of files with activity, and species richness among habitats were evaluated by 1-way ANOVAs, both for all species together and separately for every species or group of species. We used 2-way ANOVAs to assess the combined influence of habitat and zone of the city (NE, WC, or SE) on bat activity. Similar ANOVAs were conducted to assess the differences in log-transformed numbers of insects among habitats and zones. In all cases, we used Tukey tests to identify particular pairs of habitats or zones that were different. In addition, we used independent samples $t$-tests to compare bat activity (log number of calls) between small parks with white-light lamps (3 sites) and small parks with yellow illumination ( 9 sites), and between vegetated areas in large parks (6 sites) and lakeshores within large parks (6 sites).

The relationships between site-specific insect abundance and bat activity were evaluated by correlation analyses (Pearson correlation coefficient), both for all species together and for each group. In all cases, we log-transformed the total number of insects and the total number of calls (or feeding buzzes) per site. The relationship between number of taxa per site and insect abundance was evaluated by similar correlation analysis. In all cases, logarithmic transformations were in the form $\log (n+1)$. All statistical analyses were performed by using SPSS 11.0 for Windows with a significance level of 0.05 .

\section{RESULTS}

Patterns of habitat use.-We recorded 230,471 bat echolocation calls in Mexico City and the adjacent Milpa Alta natural forest. In these recordings we could recognize the following taxa: Vespertilionidae-Eptesicus fuscus, species of the genus Myotis, and an unidentified species (probably Corynorhinus mexicanus or $C$. townsendii); and Molossidae-Eumops perotis, Nyctinomops macrotis, and Tadarida brasiliensis. 

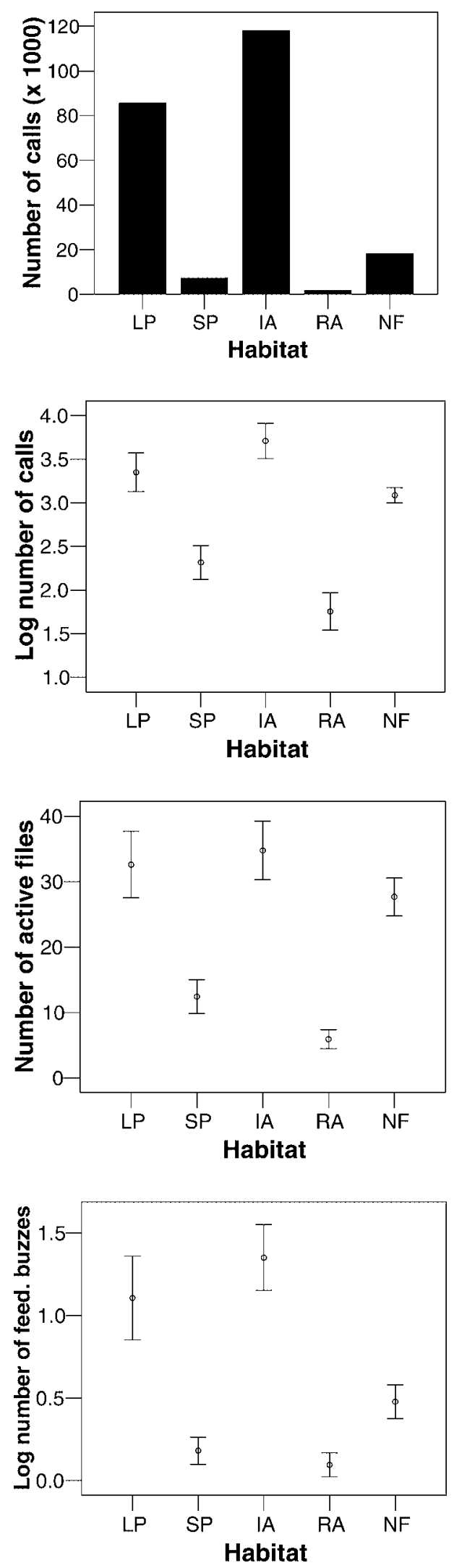

FIG. 2.-Total bat activity in 4 urban habitats and 1 natural habitat as estimated by the total number of calls recorded during the summer (720 min per habitat), log number of calls per site, number of 1-min files with activity per site, and log number of feeding buzzes per site. Number of replications (sites) per habitat is 12. Error bars represent \pm
Acoustic monitoring revealed that bats exploited available habitats at different intensities in the Mexico City region (Fig. 2 ), with each taxon displaying a distinctive pattern of habitat use (Fig. 3). We present crude numbers of calls, files with activity, and feeding buzzes per habitat in Table 2. Results of 1-way ANOVAs for the average of log-transformed number of calls and for the number of files with activity show that large parks, illuminated open areas, and natural forests were used significantly more by all groups of bats pooled together than were small parks and residential areas $(P<0.05$; Table 3; Fig. $2)$. When controlling for time of recording, large parks and illuminated open areas had significantly higher activity than the natural forest, and small parks had more activity than residential areas (Table 3). Feeding buzzes were significantly more frequent in illuminated areas and large parks compared to small parks and residential areas, and the rate was higher in illuminated areas than in the natural forest (Table 3). Within large parks, lakeshore sites exhibited significantly higher bat activity compared to areas with only vegetation $(t=3.29$, d.f. $=10, P=0.010$; Fig. 4). For small parks, those with whitelight lamps were used significantly more than parks with orange-light lamps $(t=4.38$, d.f. $=10, P=0.002$; Fig. 4).

Two taxa ( $E$. perotis and the unidentified vespertilionind) occurred exclusively in the natural forest, but we recorded no feeding buzzes from them. Statistical differences in activity estimators were significant for E. perotis $(F=88.03$, d.f. $=4$, $P<0.001$ for log-transformed number of calls, and $F=24.42$, d.f. $=4, P<0.001$ for files with activity) but not for the unidentified vespertilionid $(F=1.52$, d.f. $=4, P=0.209$, and $F=2.20, d . f .=4, P=0.081$, respectively). Activity of $E$. fuscus was restricted to the natural forest and 1 of the large parks (Fig. 3), but only the natural forest showed significantly higher activity than the other habitats (Table 3). Species of genus Myotis were largely restricted to large parks and the natural forest (Fig. 3), which produced significant differences between these and other urban habitats (Table 3). In urbanized areas, Myotis species were recorded only in three 1-min sequences. Although the total number of Myotis calls was higher in large parks, the average log number of calls and files with calls were higher in the natural forest (Fig. 3), possibly reflecting more homogeneous (spatial and temporal) use of sites in the natural forest. The importance of the natural forest for Myotis was emphasized by the number of feeding buzzes, which was significantly higher in natural forest compared to urban habitats except large parks (Table 3).

Nyctinomops macrotis used the urban-natural mosaic in the most homogeneous manner (Fig. 3). In general, N. macrotis was significantly less active in residential areas and small parks compared to large parks, illuminated areas, and natural forest (Table 3). As in Myotis, the habitat that had the highest number of calls (illuminated areas) did not show significant differences compared to the others (Table 3; Fig. 3) because activity was

$1 S E . \mathrm{LP}=$ large park; $\mathrm{SP}=$ small park; $\mathrm{IA}=$ illuminated open area; $\mathrm{RA}=$ residential area; $\mathrm{NF}=$ natural forest. 

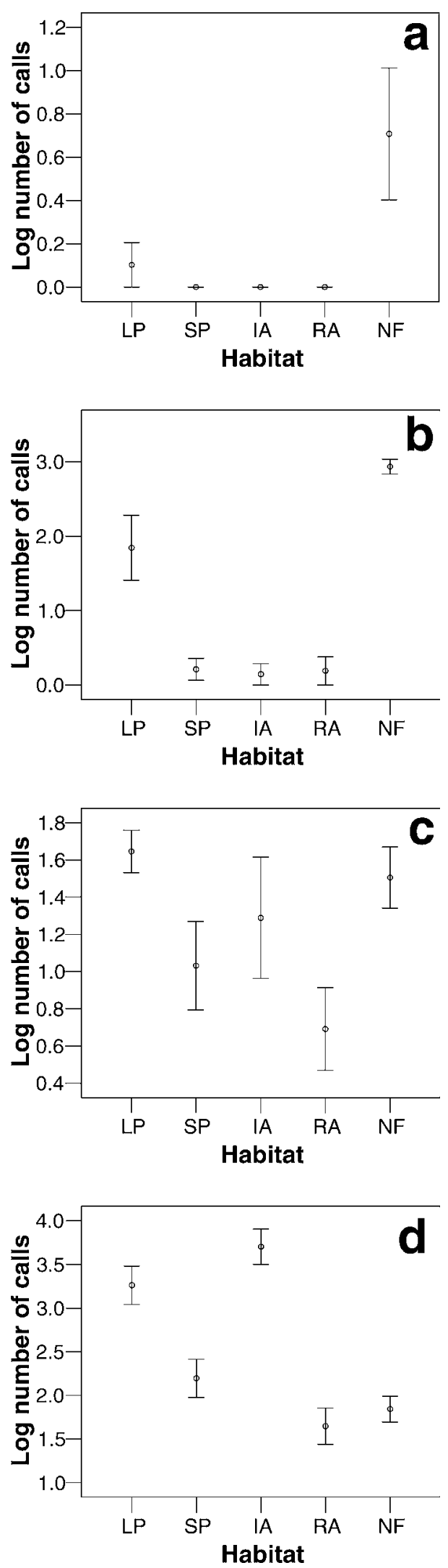

Fig. 3.-Foraging activity of a) Eptesicus fuscus, b) species of the genus Myotis, c) Nyctinomops macrotis, and d) Tadarida brasiliensis in 4 urban and 1 natural habitats as estimated by log number of calls recorded per site. An unidentified vespertilionid and Eumops perotis were only found in the natural forest. Number of replications (sites) concentrated at a few locations. The number of recorded feeding buzzes for $N$. macrotis was so low that differences between habitats were not significant (Table 3).

Tadarida brasiliensis used urban areas heavily and was most active in large parks and illuminated areas (Fig. 3). Log number of calls, files with activity, and log of feeding buzzes were significantly higher in large parks and illuminated areas than in the other habitats, including the natural forest (Table 3). The same pattern arises when controlling for time of recording, but in this case small parks had higher levels of activity than residential areas and the natural forest, and the natural forest was higher than residential areas.

The distribution of overall bat activity across habitats was similar in the 3 zones of the city. A 2-way ANOVA showed that the zone of the city (NE, WC, and SE) did not account for differences in habitat use (excluding the natural forest) as estimated by log-number of calls $(F=19.35$, d.f. $=3, P<$ 0.001 for habitat effect; $F=1.44, d . f .=2, P=0.250$ for zone effect; $F=1.07$, d.f. $=6, P=0.401$ for habitat-zone interaction). Only Myotis used habitats in each zone in significantly different ways $(F=16.12$, d.f. $=3, P<0.001$ for habitat effect; $F=9.31, d . f$. $=2, P=0.001$ for zone effect; $F=2.40$, d.f. $=6, P=0.047$ for habitat-zone interaction). The post hoc Tukey tests showed that activity of Myotis was significantly higher $(P<0.05)$ in the SE area, with most of the calls recorded in the large park (Xochimilco).

The number of taxa recorded per site through the entire sampling period (averages: 2.75 in large parks, 1.83 in small parks, 1.75 in illuminated open areas, 1.58 in residential areas, and 4.33 the natural forest) showed significant differences among habitats $(F=31.27$, d.f. $=4, P<0.001)$. The natural forest sites harbored significantly more taxa than did urban habitats $(P<0.001)$, whereas large parks supported significantly more taxa than all other urban habitats $(P<0.05)$. Thus, although total bat activity is higher in some urban habitats (large parks and illuminated areas) compared to the natural one, the latter seems to support a greater number of taxa.

Correlates of insect abundance.-Differences in the log number of insects among habitats were significant $(F=41.62$, d.f. $=4, P<0.001)$. Large parks had the highest average numbers of insects $(P<0.01)$, whereas the natural forest had significantly $(P<0.001)$ more insects than the remaining 3 urban habitats. Correlation analysis showed that total bat activity (log number of calls) was positively correlated with the $\log$ number of insects $(r=0.330, d . f .=58, P=0.010)$, but this was not true for the log number of feeding buzzes $(r=$ 0.223 , d.f. $=58, P=0.086$; Fig. 5). Correlations between bat activity and insect abundance were significant and positive for E. fuscus $(r=0.331, d . f .=58, P=0.010), E$. perotis $(r=0.372$, d.f. $=58, P=0.003)$, and $N$. macrotis $(r=0.318$, d.f. $=58, P=0.013)$, but not for $T$. brasiliensis $(r=0.128$,

per habitat is 12 . Error bars represent $\pm 1 S E$. $\mathrm{LP}=$ large park; $\mathrm{SP}=$ small park; IA = illuminated open area; $\mathrm{RA}=$ residential area; $\mathrm{NF}=$ natural forest. 
TABLE 2.-Absolute numbers of calls, files with activity, and feeding buzzes recorded per habitat for each bat species or group of species. The percentage of files with activity in relation to the number of files recorded (3,600 in total and 720 per habitat) is presented in parentheses.

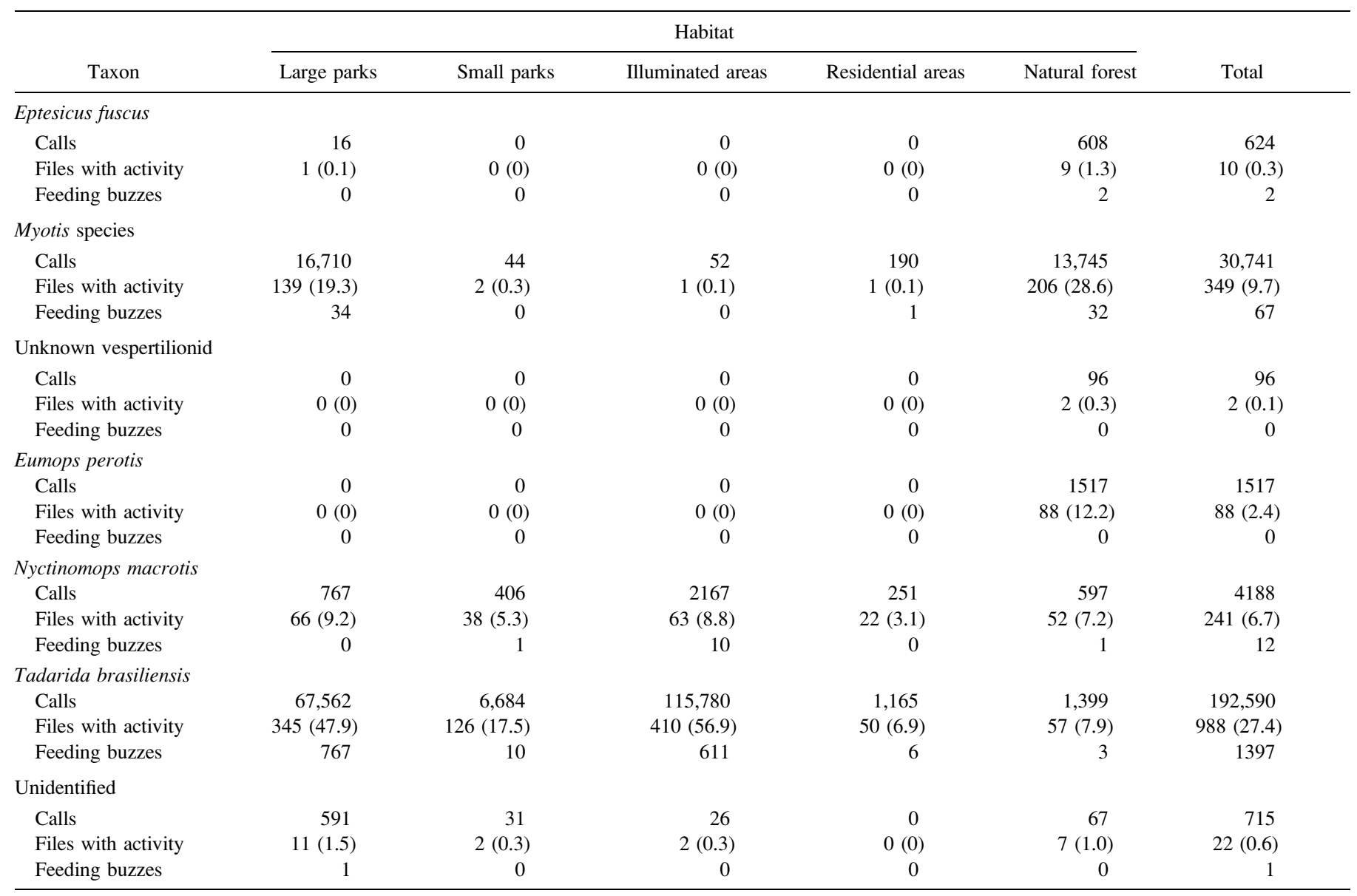

d.f. $=58, P=0.329$ ). Both log numbers of calls and feeding buzzes of Myotis were strongly correlated with insect abundance $(r=0.637, d . f .=58, P<0.001$, and $r=0.472$, d.f. $=58, P<0.001$, respectively). Furthermore, total number of taxa per site also was strongly correlated with insect abundance $(r=0.571, d . f .=58, P<0.001$; Fig. 5). However, these correlations must be taken cautiously because the numbers of insects sampled in illuminated areas most probably do not reflect their real relative abundance. When illuminated sites are removed from analysis, all correlations become significant the 0.05 level, in most cases with increased coefficients of correlation.

\section{Discussion}

Although bats may be among the most abundant wild mammals in urban areas around the world, our study shows that high levels of urbanization have negative consequences for most species of insectivorous bats. Our results agree with past research on bats and other vertebrates showing that a general effect of urbanization is reduction of species richness and an increase in abundance of a few opportunistic species (e.g., Gaisler et al. 1998; Gilbert 1989; Savard et al. 2000). Although this pattern may not be true in some cities (depending on the nature of the surrounding landscape-Clergeau et al. 1998; Gehrt and Chelsvig 2003; Savard et al. 2000), this is what we would expect in Mexico City, considering its intense level of urbanization and the high regional biodiversity. Because of its geographical position and topography, Mexico City is surrounded by a variety of natural habitats where temperate and tropical elements combine in a relatively small area (Ezcurra 1998). Rural activities, including cultivation of native crops, ornamental flowers, and fruit trees, as well as the practice of an ancestral agricultural method in lacustrine areas ("chinampas"), provide a variety of resources that are beneficial for many native species (Ezcurra 1998). For bats, this particularly high habitat diversity is reflected in the high number of species that historically have been captured in the suburban, rural, and natural areas surrounding the city (29 species including insectivores, nectarivore-pollinivores, and frugivores-Sánchez et al. 1989).

Patterns of habitat use within the urban mosaic were consistent with many studies showing that larger, more vegetated areas support richer faunas but not necessarily higher abundances than do smaller patches of vegetation and built-up sites (e.g., Clergeau et al. 1998; Frankie and Ehler 1978; Gaisler et al. 1998; Gavareski 1976; Gehrt and Chelsvig 2003; Germaine and Wakeling 2001; Hardy and Dennis 1999; 
TABLE 3. - Statistical parameters obtained by comparing bat activity estimators between habitats by using 1-way analysis of variance (ANOVAs). Only bat taxa present in more than 1 habitat are shown. Log-C $=$ log-number of calls; log-C (time) $=\log$-number of calls when controlling for time (analysis of covariance); $\mathrm{AF}=$ files with activity; Log-FB = log-number of feeding buzzes; $\mathrm{LP}=$ large park; $\mathrm{SP}=\mathrm{small}$ park; $\mathrm{IA}=$ illuminated area; $\mathrm{RA}=$ residential area; $\mathrm{NF}=$ natural forest.

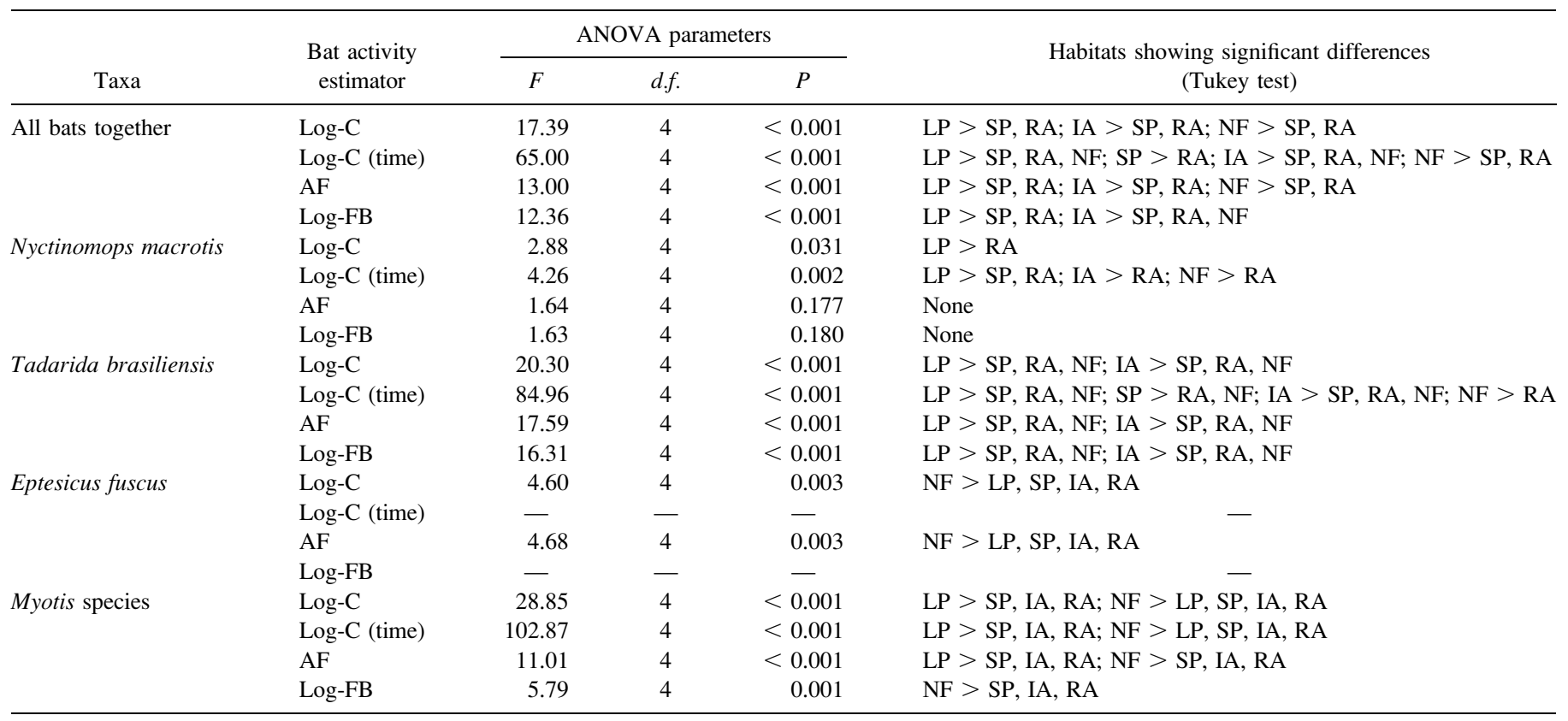

Kozlov 1996; McGeoch and Chown 1997). Distribution of historical records emphasizes the importance of green areas for bats in Mexico City, because most of the specimens have been collected in the suburbs or in areas with relicts of natural vegetation, particularly from western and southern zones of the city (Sánchez et al. 1989). Similar spatial patterns of species richness and abundance have been reported for the bird assemblage of Mexico City, where southern and western areas of the city, particularly those in the periphery, support highly diverse bird faunas (Nocedal 1987).

Although well-vegetated areas are the main foraging habitat for insectivorous bats within urban landscapes (Everette et al. 2001; Furlonger et al. 1987; Gaisler et al. 1998; Geggie and Fenton 1985; Gehrt and Chelsvig 2003; Kurta and Teramino 1992), sites illuminated with white-light lamps are strongly preferred by some species (Furlonger et al. 1987; Gaisler et al. 1998). Vegetated areas are important because insect productivity increases with vegetation coverage (e.g., Faeth and Kane 1978; Hardy and Dennis 1999; Kozlov 1996; McGeoch and Chown 1997; this study), and proximity of streetlamps to vegetation may be necessary to attract bats in large urban settings (Russo and Jones 2003; Rydell 1992; Rydell and Racey 1995). Observations of Lasiurus borealis, L. cinereus (Furlonger et al. 1987), and E. fuscus (Geggie and Fenton 1985 ) foraging intensively around streetlamps in rural but not in urban areas support this hypothesis. However, we found high levels of bat activity in illuminated sites located in wellurbanized areas up to $5 \mathrm{~km}$ away from large patches of vegetation, suggesting that insect abundance can be more important than proximity to vegetation. Although we found that small parks were not important for foraging bats, we propose that even small green areas can be important for promoting insect productivity in the city.

Our results clearly show that different species of bats exploit the urban-natural landscape in very distinctive ways. Molossids, particularly $T$. brasiliensis and $N$. macrotis, probably benefit most from the creation of urban features, because they were commonly detected at most sites in all habitats. Roosts could be a factor promoting the presence of molossids in cities, because buildings and other structures such as bridges offer many crevicelike sites that resemble natural molossid roosts (Best et al. 1996; Milner et al. 1990; Wilkins 1989). Additionally, we can assume that virtually every site in the city is accessible to molossids, which can travel long distances to reach foraging areas and fly at very high altitudes (Griffin and Thompson 1986; Wilkins 1989).

Flight and echolocation performance may be the most important factors constraining molossids from using the most profitable patches of food in the city. In general, these species have narrow and long wings (high aspect ratio and high wing loading), which make their flight fast and straight but not very maneuverable (Norberg and Rayner 1987; Wilkins 1989). The long or relatively long, narrow-band, low-frequency echolocation calls of molossids are appropriate for detecting large prey and other objects from relatively long distances (Fenton 1990). Together, flight and echolocation features should allow molossids to exploit open habitats where larger prey are abundant. Flight speed and maneuverability of species (a factor related to body size-Norberg and Rayner 1987) also could explain why the smallest molossid (T. brasiliensis) exploited patches of food that were close to ground level (vegetated and illuminated areas). It is possible that the larger and less 

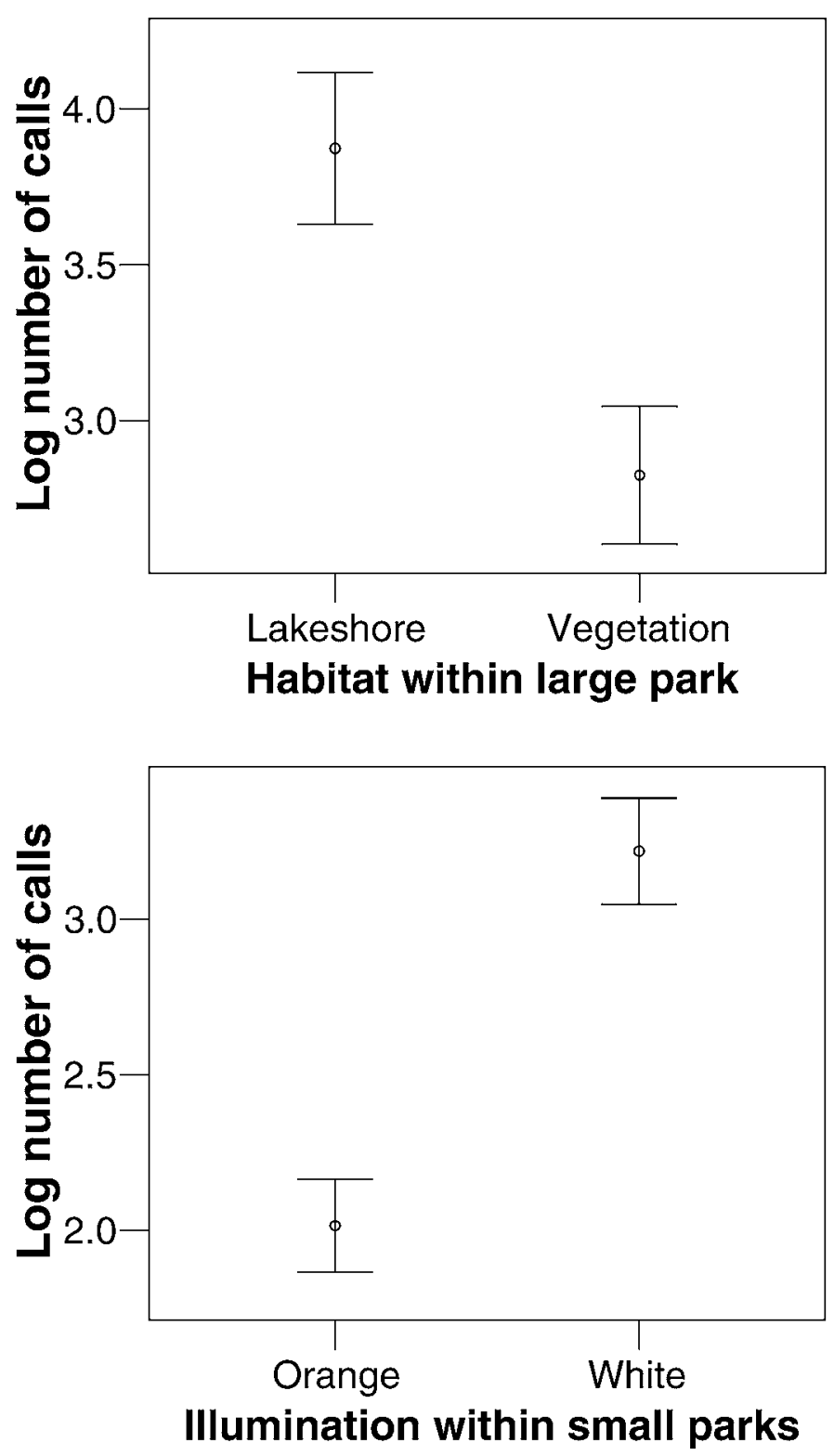

Fig. 4.-Total bat activity (as estimated by the log number of calls recorded per site) in urban parks with different characteristics (number of replicates shown in parentheses): lakeshore areas within large parks (6), vegetated areas within large parks (6), small parks with white-light lamps (3), and small parks with orange-light lamps (9). Error bars represent $\pm 1 S E$. In both cases differences were significant at the 0.05 level.

maneuverable $N$. macrotis did not detect patches of prey close to the ground and other objects because it flew higher. The same argument could apply to the even larger E. perotis, which has been captured in the city (Sánchez et al. 1989), but whose calls were not detected there during this study. All 3 species of molossids were encountered in the surrounding woodland, demonstrating that they are not just city bats.

Some studies have shown that small vespertilionids (Plecotus, Corynorhinus, and Myotis) rarely occur in urban environments or occur only in well-vegetated areas of cities (Evelyn et al. 2004; Furlonger et al. 1987; Gaisler et al. 1998; Gehrt and Chelsvig 2003). In this study, the few sequences of
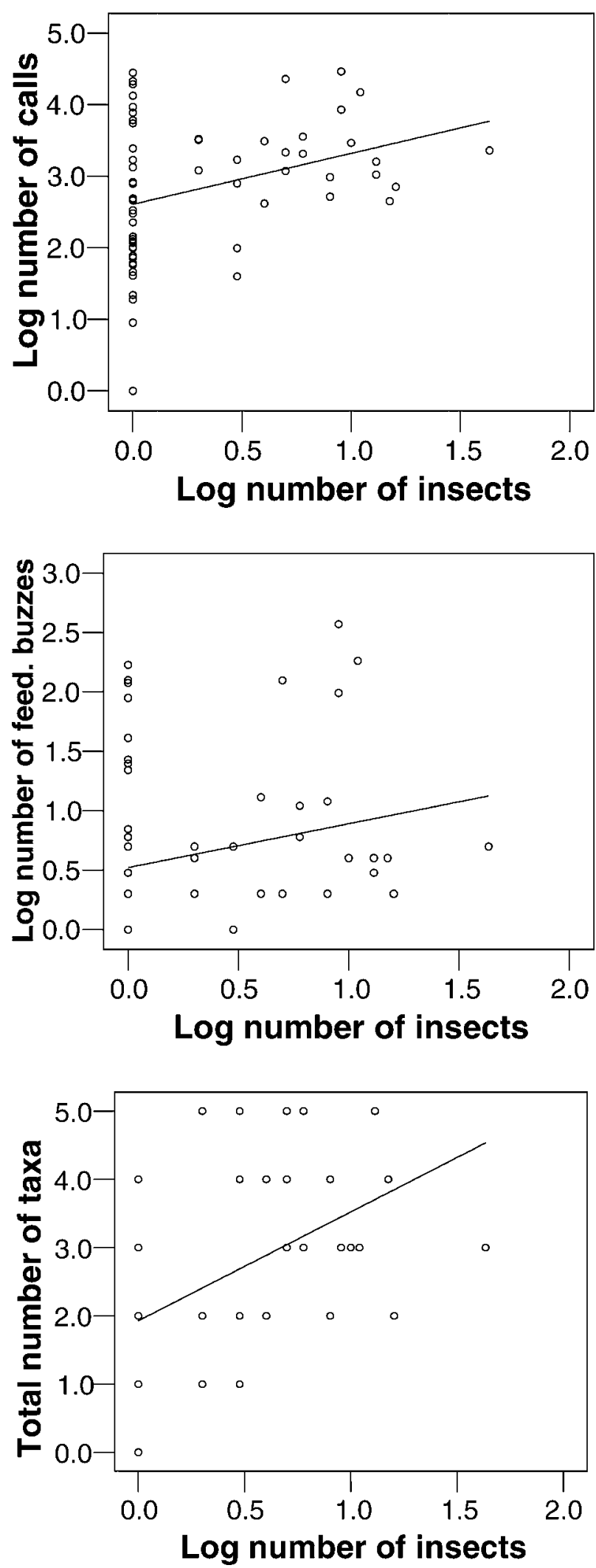

Fig. 5.-Correlations of relative insect abundance (log numbers) with total bat activity (log number of calls), total number of feeding buzzes, and number of taxa recorded per site. Each point represents 1 of the 60 sampling sites. Correlations were significant for bat activity $(r=330)$ and number of taxa recorded per site $(r=0.571)$. 
Myotis recorded in urban areas came from wealthy residential neighborhoods of southern Mexico City, which encompasses districts characterized by having lower population densities (ranging from 1,700 to 12,200 persons $/ \mathrm{km}^{2}$ - INEGI 2001) and a higher proportion of green areas than central and northern districts of the city $\left(13,000-18,000\right.$ persons/ $/ \mathrm{km}^{2}$ - INEGI 2001). These findings agree with those of other studies conducted in natural or seminatural landscapes showing that species of Myotis, Plecotus, and Corynorhinus forage and commute close to vegetation, typically avoiding open areas (Adam et al. 1994; Buford and Lacki 1995; de Jong 1995; Ekman and de Jong 1996; Entwistle et al. 1996; Furlonger et al. 1987; Limpens and Kapteyn 1991; Vaughan et al. 1997). The wing morphology of these small vespertilionids suggests a slow and maneuverable flight (Norberg and Rayner 1987), so they are indeed expected to be active in highly cluttered areas. Additionally, species of Plecotus and Corynorhinus and some species of Myotis produce low-intensity, short, broad-band echolocation calls, which should be effective for operating in clutter (Fenton 1990). However, neither flight nor echolocation parameters explain why we did not record these bats more often along urban tree lines while they were commuting or in other patches of food such as clusters of insects around streetlamps.

We suggest that small vespertilionids avoid using large, well-urbanized areas because they perceive human-made linear features as "hostile areas" because of their habit of flying slow and close to the ground (below $12 \mathrm{~m}$, but usually below $5 \mathrm{~m}-$ Fenton and Barclay 1980; Fitch et al. 1981; Kurta 1982), which in turn could be related with their short range of detection (e.g., Kalko and Schnitzler 1993; Verboom and Spoelstra 1999). Flying under these circumstances in a highly transited and active city could be dangerous for bats, particularly because they would risk being hit by a vehicle or being bothered by people. Avoidance of well-illuminated areas as a mechanism to reduce predation risk (Rydell and Racey 1995) also could explain the low abundance of vespertilionids in the core of the city.

Our results suggest that patterns of urbanization such as those in Mexico City have negative consequences for most species of insectivorous bats. The only species that seem to tolerate heavy levels of urbanization are those with flexible roost requirements whose flight abilities allow them to reach scarce but predictable sources of food. Therefore, molossids are expected to be usual inhabitants of city cores and other heavily urbanized areas in tropical and subtropical regions. However, it is unknown if these species are able to maintain stable populations within large urban areas. Studies on long-term population dynamics and demography of urban bats are needed to understand the ultimate influence of megaurbanization on bat species.

\section{Resumen}

Analizamos los patrones de uso de hábitat por murciélagos insectívoros en la Ciudad de México, una de las ciudades más grandes y más pobladas del mundo. Se pusieron a prueba las siguientes hipótesis: los parches con mayor abundancia de alimento, esperados en las áreas con mayor cobertura vegetal, presentan mayores niveles de actividad de murciélagos; y las especies de vuelo rápido son las más beneficiadas por la urbanización. Comparamos los niveles de actividad de murciélagos insectívoros así como la abundancia relativa de insectos en 5 hábitats: parques grandes, parques chicos, áreas abiertas iluminadas, zonas habitacionales y bosque natural. Realizamos el muestreo de murciélagos e insectos cada 2 semanas en 12 sitios por hábitat durante el verano de 2002. Evaluamos la actividad de murciélagos mediante el análisis de 3,600 secuencias de sonido de 1 min de duración. El nùmero promedio de taxa por sitio fue significativamente más alto en el bosque natural que en los hábitats urbanos, pero los niveles de actividad total fueron significativamente más altos en los parques grandes y en las áreas iluminadas que en los parques chicos, zonas habitacionales y bosque natural. Los murciélagos vespertiliónidos (Eptesicus fuscus, Myotis y una especie no identificada), junto con Eumops perotis, fueron registrados casi exclusivamente en las áreas verdes de mayor extensión (parques grandes y bosque natural). El molósido Nyctinomops macrotis utilizó el mosaico urbano-natural de manera mucho más homogénea, mientras que Tadarida brasiliensis utilizó sitios urbanos (áreas iluminadas y parques grandes) con mayor frecuencia. La abundancia de insectos fue más alta en parques grandes y en el bosque natural, y se correlacionó significativamente con la actividad total de murciélagos y con el nùmero de taxa registrado por sitio. Los patrones de uso de hábitat observados pueden ser explicados tomando en cuenta las características del vuelo y ecolocalización de cada especie. Aunque algunas especies explotaron de manera exitosa sitios altamente urbanizados, se requiere de extensas áreas verdes para mantener la mayor diversidad de murciélagos insectívoros en la Ciudad de México.

\section{ACKNOWLEDGMENTS}

We are indebted to A. de Villa-Meza for her assistance at every stage of the fieldwork. Thanks to all the people who collaborated during the bat monitoring in Mexico City, especially to J. Cruzado, S. Biscardi, C. Galicia, M. A. Hernández, B. Victoria, and H. Zarza. F. J. Navarro-Frías provided valuable information about bats of Milpa Alta. We acknowledge Program for Conservation of Mexican Bats (PCMM), R. A. Medellín and L. Avila for kindly providing logistical support in Mexico City. Thanks to Parque Ecológico de Xochimilco and Dirección de Bosques Urbanos del Distrito Federal for allowing us to work in urban parks. B. J. Stutchbury, N. D. Yan, and D. Russo provided helpful comments at different stages of the manuscript. Grants were provided by Consejo Nacional de Ciencia y Tecnología (Mexico), Natural Sciences and Engineering Research Council of Canada, and York University (Canada).

\section{Literature Cited}

AdAm, M. D., M. J. LACKI, AND T. G. BARNES. 1994. Foraging areas and habitat use of the Virginia big-eared bat in Kentucky. Journal of Wildlife Management 58:462-469.

Animal Care and Use Committee. 1998. Guidelines for the capture, handling, and care of mammals as approved by the American Society of Mammalogists. Journal of Mammalogy 79:1416-1431.

Arita, H. T., ANd J. Ortega. 1998. Neotropical-Nearctic limits in Middle America as determined by distributions of bats. Journal of Mammalogy 79:772-783. 
Avila-Flores, R. 2003. Habitat use by foraging insectivorous bats in a large urban mosaic. M.S. thesis, York University, Toronto, Ontario, Canada.

Barclay, M. R., J. H. Fullard, AND D. S. Jacobs. 1999. Variation in the echolocation calls of the hoary bat (Lasiurus cinereus): influence of body size, habitat structure, and geographic location. Canadian Journal of Zoology 77:530-534.

Bell, G. P. 1980. Habitat use and response to patches of prey by desert insectivorous bats. Canadian Journal of Zoology 58: 1876-1883.

Best, T. L., W. M. Kiser, AND P. W. FreEman. 1996. Eumops perotis. Mammalian Species 534:1-8.

BETTS, B. J. 1998. Effects of interindividual variation in echolocation calls on identification of big brown and silver-haired bats. Journal of Wildlife Management 62:1003-1010.

Blake, D., A. M. Hutson, P. A. Racey, J. Rydell, and J. R. SPEAKMAN. 1994. Use of lamplit roads by foraging bats in southern England. Journal of Zoology (London) 234:453-462.

BufORD, L. S., AND M. J. LACKI. 1995. Habitat use by Corynorhinus townsendii virginianus in the Daniel Boone National Forest. American Midland Naturalist 134:340-345.

Clergeau, P., J. P. L. Savard, G. Mennechez, and G. Falardeau. 1998. Bird abundance and diversity along an urban-rural gradient: a comparative study between two cities on different continents. Condor 100:413-425.

DE JONG, J. 1995. Habitat use and species richness of bats in a patchy landscape. Acta Theriologica 40:237-248.

EkMAN, M., AND J. DE JoNG. 1996. Local patterns of distribution and resources utilization of 4 bat species (Myotis brandti, Eptesicus nilssoni, Plecotus auritus and Pipistrellus pipistrellus) in patchy and continuous environments. Journal of Zoology (London) 238:571-580.

Entwistle, A. C., P. A. Racey, and J. R. Speakman. 1996. Habitat exploitation by a gleaning bat, Plecotus auritus. Philosophical Transactions of the Royal Society of London, B. Biological Sciences 351:921-931.

Evelyn, M. J., D. A. Stiles, And R. A. Young. 2004. Conservation of bats in suburban landscapes: roost selection by Myotis yumanensis in a residential area in California. Biological Conservation 115: 463-473.

Everette, A. L., T. J. O’Shea, L. E. Ellison, L. A. Stone, and J. L. MCCANCE. 2001. Bats use of a high-plains urban wildlife refuge. Wildlife Society Bulletin 29:967-973.

Ezcurra, E. 1998. De las chinampas a la megalopolis: el medio ambiente en la cuenca de México. 2nd ed. La Ciencia Para Todos, Fondo de Cultura Económica 91:1-119.

Ezcurra, E., AND M. Mazari-Hiriart. 1996. Are megacities viable? A cautionary tale from Mexico City. Environment January-February: 6-15, 26-32.

Faeth, S. H., And T. C. Kane. 1978. City parks as islands for Diptera and Coleoptera. Oecologia 32:127-133.

Fenton, M. B. 1990. The foraging behaviour and ecology of animaleating bats. Canadian Journal of Zoology 68:411-422.

Fenton, M. B., AND R. M. R. Barclay. 1980. Myotis lucifugus. Mammalian Species 142:1-8.

Fenton, M. B., AND G. K. Morris. 1976. Opportunistic feeding by desert bats (Myotis spp.). Canadian Journal of Zoology 54:526-530.

FERNÁNDEZ-JuRICIC, E. 2000. Avifaunal use of wooded streets in an urban landscape. Conservation Biology 14:513-521.

FERNÁNDEZ-JURICIC, E., AND J. JOKIMÄKI. 2001. A habitat island approach to conserving birds in urban landscapes: case studies from southern and northern Europe. Biodiversity and Conservation 10:2023-2043.
Fitch, J. H., K. A. Shump, JR., AND A. U. Shump. 1981. Myotis velifer. Mammalian Species 149:1-5.

Frankie, G. W., AND L. E. Ehler. 1978. Ecology of insects in urban environments. Annual Review of Entomology 23:367-387.

Furlonger, C. L., H. J. Dewar, And M. B. Fenton. 1987. Habitat use by foraging insectivorous bats. Canadian Journal of Zoology 65 : 284-288.

Gaisler, J., J. Zukal, Z. RehaK, And M. Homolka. 1998. Habitat preference and flight activity of bats in a city. Journal of Zoology (London) 244:439-445.

GAVARESKi, C. A. 1976. Relation of park size and vegetation to urban bird populations in Seattle, Washington. Condor 78:375-382.

GegGie, J. F., AND M. B. Fenton. 1985. A comparison of foraging by Eptesicus fuscus (Chiroptera: Vespertilionidae) in urban and rural environments. Canadian Journal of Zoology 63:263-266.

GehrT, S. D., AND J. E. Chelsvig. 2003. Bat activity in an urban landscape: patterns at the landscape and microhabitat scale. Ecological Applications 13:939-950.

Germaine, S. S., AND B. F. Wakeling. 2001. Lizard species distributions and habitat occupation along an urban gradient in Tucson, Arizona, USA. Biological Conservation 97:229-237.

GILBERT, O. L. 1989. The ecology of urban habitats. Chapman \& Hall, London, United Kingdom.

Griffin, D. R., And D. Thompson. 1986. High altitude echolocation of insects by bats. Behavioral Ecology and Sociobiology 10: 303-306.

Griffin, D. R., F. A. Webster, and C. R. Michael. 1960. The echolocation of flying insects by bats. Animal Behaviour 8:141-154.

Hardy, P. B., and L. H. Dennis. 1999. The impact of urban development on butterflies within a city region. Biodiversity and Conservation 8:1261-1279.

Hickey, M. B. C., L. Acharya, and S. Pennington. 1996. Resource partitioning by two species vespertilionid bats (Lasiurus cinereus and Lasiurus borealis) feeding around street lights. Journal of Mammalogy 77:325-334.

INEGI (Instituto Nacional de Estadística, Geografía e InFORMÁtICA). 2001. Estadísticas del medio ambiente del Distrito Federal y Zona Metropolitana 2000. Instituto Nacional de Estadística, Geografía e Informática, Mexico City, Mexico.

ЈокIмÄкI, J. 1999. Occurrence of breeding bird species in urban parks: effects of park structure and broad-scale variables. Urban Ecosystems 3:21-34.

Jones, G., AND A. F. JAYNE. 1988. Bats in Avon: their distribution in relation to the urban environment. Proceedings of the Bristol Naturalists' Society 48:31-51.

Kalko, E. K. V., And H.-U. Schnitzler. 1993. Plasticity in echolocation signals of European pipistrelle bats in search flight: implications for habitat use and prey detection. Behavioral Ecology and Sociobiology 33:415-428.

Kozlov, M. V. 1996. Patterns of forest insect distribution within a large city: microlepidoptera in St. Peterburg, Russia. Journal of Biogeography 23:95-103.

KunZ, T. H. 1988. Methods of assessing the availability of prey to insectivorous bats. Pp. 191-210 in Ecological and behavioral methods for the study of bats (T. H. Kunz, ed.). Smithsonian Institution Press, Washington, D.C.

KuRTA, A. 1982. Flight patterns of Eptesicus fuscus and Myotis lucifugus over a stream. Journal of Mammalogy 63:335-337.

Kurta, A., And J. A. Teramino. 1992. Bat community structure in an urban park. Ecography 15:257-261.

LimPENS, H.J.G.A., AND K. KAPTEYN. 1991. Bats, their behaviour and linear landscape elements. Myotis 29:39-48. 
McGeoch, M. A., AND S. L. Chown. 1997. Impact of urbanization on a gall-inhabiting Lepidoptera assemblage: the importance of reserves in urban areas. Biodiversity and Conservation 6:979-993.

Miller, B. W. 2001. A method for determining relative activity of free flying bats using a new activity index for acoustic monitoring. Acta Chiropterologica 3:93-105.

MiLNER, J., C. JoNES, AND J. K. JoNES, JR. 1990. Nyctinomops macrotis. Mammalian Species 351:1-4.

Navarro, F. J. 2002. Los mamíferos silvestres de la delegación Milpa Alta. B.S. thesis, Escuela Nacional de Ciencias Biológicas, Instituto Politecnico Nacional, Mexico City, Mexico.

Nocedal, J. 1987. Las comunidades de pájaros y su relación con la urbanización en la ciudad de México. Pp. 73-109 in Aportes a la ecología urbana de la ciudad de México (E. Rapoport and I. R. López-Moreno, eds.). Limusa, Mexico City, Mexico.

NORBERG, U. M., AND J. M. V. RAYNER. 1987. Ecological morphology and flight in bats (Mammalia; Chiroptera): wing adaptations, flight performance, foraging strategy and echolocation. Philosophical Transactions of the Royal Society of London, B. Biological Sciences 316:335-427.

OBRIST, M. K. 1995. Flexible bat echolocation: the influence of individual, habitat and conspecifics on sonar signal design. Behavioral Ecology and Sociobiology 36:207-219.

O'Farrell, M. J., C. Corben, and W. L. Gannon. 2000. Geographic variation in the echolocation calls of the hoary bat (Lasiurus cinereus). Acta Chiropterologica 2:185-195.

PrimACK, R. B. 2000. A primer of conservation biology. 2nd ed. Sinauer Associates, Inc., Sunderland, Massachusetts.

RAtCliffe, J. M., ET AL. 2004. Conspecifics influence call design in the Brazilian free-tailed bat, Tadarida brasiliensis. Canadian Journal of Zoology 82:966-971.

Russo, D., AND G. JONES. 2003. Use of foraging habitats by bats in a Mediterranean area determined by acoustic surveys: conservation implications. Ecography 26:197-209.

RYDELL, J. 1992. Exploitation of insects around streetlamps by bats in Sweden. Functional Ecology 6:744-750.
Rydell, J., AND P. A. RaCEY. 1995. Street lamps and the feeding ecology of insectivorous bats. Symposia of the Zoological Society of London 67:291-307.

SÁnchez, O., G. López-Ortega, And R. LóPez-Wilchis. 1989. Murciélagos de la Ciudad de México y sus alrededores. Pp. 141165 in Ecología urbana (R. Gío-Argáez, I. Hernández-R., and E. Sáinz-H., eds.). DDF, CONACyT, UNAM, SEDUE, SEP, SMHN, and UAM, Mexico City, Mexico.

Savard, J. P. L., P. Clergeau, and G. Mennechez. 2000. Biodiversity concepts and urban ecosystems. Landscape and Urban Planning 48:131-142.

Schnitzler, H. U., E. Kalko, L. Miller, and A. SurlykKe. 1987. The echolocation and hunting behavior of the bat, Pipistrellus kuhli. Journal of Comparative Physiology. A. Sensory, Neural, and Behavioral Physiology 161:267-274.

Sodhi, N. S., C. Briffett, L. Kong, and B. Yuen. 1999. Bird use of linear areas of a tropical city: implications for park connector design and management. Landscape and Urban Planning 45: 123-130.

Vaughan, N., G. Jones, and S. Harris. 1997. Habitat use by bats (Chiroptera) assessed by means of a broad-band acoustic method. Journal of Applied Ecology 34:716-730.

Verboom, B., AND K. Spoelstra. 1999. Effects of food abundance and wind on the use of tree lines by an insectivorous bat, Pipistrellus pipistrellus. Canadian Journal of Zoology 77: 1393-1401.

WaLSH, A. L., AND S. HARRIS. 1996. Foraging habitat preferences of vespertilionid bats in Britain. Journal of Applied Ecology 33: 508-518.

WILKINS, K. T. 1989. Tadarida brasiliensis. Mammalian Species $331: 1-10$.

Submitted 28 August 2004. Accepted 19 April 2005.

Associate Editor was William L. Gannon. 